\title{
INTEGRATING WOMEN AND ENTREPRENEURSHIP FOR SUSTAINABLE RURAL WATER SUPPLY SCHEMES IN SRI LANKA
}

Nirojan Donald Sinclair

NO. 71

ADB SOUTH ASIA

June 2020

\section{WORKING PAPER SERIES}




\section{ADB South Asia Working Paper Series}

\section{Integrating Women and Entrepreneurship for Sustainable Rural Water Supply Schemes in Sri Lanka}

Nirojan Donald Sinclair

No. 71 | June 2020
Nirojan Donald Sinclair is a project officer

(Infrastructure) at the Sri Lanka Resident Mission,

Asian Development Bank (ADB).

The author thanks staff of the Sri Lanka Resident Mission and the Urban and Water Division, South Asia Department, ADB who gave useful comments and suggestions to this working paper; and Samanmalee

Swarnalatha (consultant) who collected field data. 
(C) 2020 Asian Development Bank 6 ADB Avenue, Mandaluyong City, 1550 Metro Manila, Philippines

Tel +632 8632 4444; Fax +63286362444

www.adb.org

Some rights reserved. Published in 2020.

Printed in the Philippines

ISSN 2313-5867 (print), 2313-5875 (electronic)

Publication Stock No. WPS200169-2

DOI: http://dx.doi.org/10.22617/WPS200169-2

The views expressed in this publication are those of the authors and do not necessarily reflect the views and policies of the Asian Development Bank (ADB) or its Board of Governors or the governments they represent.

ADB does not guarantee the accuracy of the data included in this publication and accepts no responsibility for any consequence of their use. The mention of specific companies or products of manufacturers does not imply that they are endorsed or recommended by ADB in preference to others of a similar nature that are not mentioned.

By making any designation of or reference to a particular territory or geographic area, or by using the term "country" in this document, $A D B$ does not intend to make any judgments as to the legal or other status of any territory or area.

This work is available under the Creative Commons Attribution 3.0 IGO license (CC BY 3.0 IGO) https://creativecommons.org/licenses/by/3.0/igo/. By using the content of this publication, you agree to be bound by the terms of this license. For attribution, translations, adaptations, and permissions, please read the provisions and terms of use at https://www.adb.org/terms-use\#openaccess.

This CC license does not apply to non-ADB copyright materials in this publication. If the material is attributed to another source, please contact the copyright owner or publisher of that source for permission to reproduce it. ADB cannot be held liable for any claims that arise as a result of your use of the material.

Please contact pubsmarketing@adb.org if you have questions or comments with respect to content, or if you wish to obtain copyright permission for your intended use that does not fall within these terms, or for permission to use the ADB logo.

The ADB South Asia Working Paper Series is a forum for ongoing and recently completed research and policy studies undertaken in ADB or on its behalf. It is meant to enhance greater understanding of current important economic and development issues in South Asia, promote policy dialogue among stakeholders, and facilitate reforms and development management.

The ADB South Asia Working Paper Series is a quick-disseminating, informal publication whose titles could subsequently be revised for publication as articles in professional journals or chapters in books. The series is maintained by the South Asia Department. The series will be made available on the ADB website and on hard copy.

Corrigenda to ADB publications may be found at http://www.adb.org/publications/corrigenda.

Note:

In this publication, “\$” refers to United States dollars and "SLRs" to Sri Lanka rupees. 


\section{CONTENTS}

TABLES, FIGURES, AND BOXES iv

ABBREVIATIONS V V V V V V V V

CURRENCY EQUIVALENTS

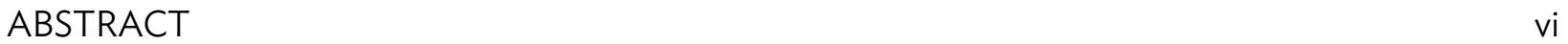

$\begin{array}{ll}\text { I. INTRODUCTION } & 1\end{array}$

II. INTEGRATION OF WOMEN IN RURAL WATER SUPPLY OPERATIONS 2

III. ENTREPRENEURSHIP AS A SOLUTION TO

SUSTAINABLE RURAL WATER SUPPLY SCHEMES

IV. $\quad$ THE SRI LANKAN RURAL WATER SUPPLY CONTEXT 6

V. ADB'S ASSISTANCE TO SRI LANKAN RURAL WATER SUPPLY SCHEMES

VI. EVIDENCE OF WOMEN WITH ENTREPRENEURIAL TRAITS 8

IN SRI LANKAN RURAL WATER SUPPLY SCHEMES

A. Case Study-based Analysis 8

B. Analysis Findings 10

VII. CONCLUSIONS AND RECOMMENDATIONS 22

$\begin{array}{ll}\text { REFERENCES } & 24\end{array}$ 


\section{TABLES, FIGURES, AND BOXES}

\section{TABLES}

$1 \quad$ Examples of Water, Sanitation, and Hygiene Enterprises at Rural Level

2 Details of Community-Based Organizations and Rural Water Supply Schemes

Taken for Case Study

\section{FIGURES}

$1 \quad$ Basic Entrepreneurial Traits 5

2 Composition of Women in Community-Based Organizations' Top Management 11 (Executive Committees)

3 Composition of Women in Rural Water Supply Scheme Operational Teams 11

\section{BOXES}

$1 \quad$ A Woman's Passion to Run a Rural Water Business 13

2 More Than Just a Farmer and a Housewife 14

3 A Seasoned Leader, Teacher, and Risk Taker 16

4 A Female Intrapreneur 19 


\section{ABBREVIATIONS}

$\begin{array}{ll}\text { ADB } & \text { Asian Development Bank } \\ \text { CBO } & \text { community-based organization } \\ \text { CKD } & \text { chronic kidney disease } \\ \text { DNCWS } & \text { Department of National Community Water Supply } \\ \text { MCPWSHE } & \text { Ministry of City Planning, Water Supply, and Higher Education } \\ \text { NGO } & \text { nongovernment organization } \\ \text { NWSDB } & \text { National Water Supply and Drainage Board } \\ \text { RWSS } & \text { rural water supply scheme } \\ \text { UN } & \text { United Nations } \\ \text { WASH } & \text { water, sanitation, and hygiene }\end{array}$

$\begin{gathered}\text { CURRENCY EQUIVALENTS } \\ \text { As of } 30 \\ \text { December } 2019\end{gathered}$
$\begin{array}{ll}\$ 1.00= & \text { SLRs } 181.550 \\ \text { SLRs } 1.00= & \$ 0.006\end{array}$




\begin{abstract}
Rural water supply schemes (RWSSs) must ensure post-implementation sustainability. Among other requirements for sustainability, one is the involvement of women in actively managing rural water operations. Another is managing rural water operations as a business model, which would call for people with entrepreneurial skills. The combination of these (women's involvement and operations as a business model) is expected to bring a positive cycle of development and mutual benefits.

This working paper, based on case studies, tries to qualitatively analyze the proposition of integration of water, women, and rural entrepreneurship into RWSSs and to determine whether this has been successful in the Sri Lankan context. A small sample consisting of 11 RWSSs from the Anuradhapura and Polonnaruwa districts were taken for this study.

The findings indicate that the local RWSSs have become a good platform for rural women to practice their inherent entrepreneurial skills, and this benefits the water supply schemes as well. However, women who lead in managing these RWSSs do not seem to identify themselves as emerging entrepreneurs, but rather as better leaders.

The study further finds that the project designs had enough room to integrate women into the RWSS operations, but not necessarily as entrepreneurs. Women who manage these RWSSs feel that assistance from a catalyst could better translate their entrepreneurial skills into practical actions.

To further integrate women with entrepreneurial skills into the local RWSSs, the government may need to revise its policies toward RWSSs to specifically include entrepreneurial thoughts and to especially provision rural women entrepreneurs; local entrepreneurial development institutes ought to become stakeholders of RWSS projects; new projects need to be designed from the inception stage to consider entrepreneurial skills as a main component of RWSS operational activities; women who are already in RWSS operations should be empowered through customized training programs to bring out their inherited entrepreneurial skills; and potential resources from current and future funding, not necessarily meant for the development of water sector, but for others, shall be tapped to assist the RWSSs in improving their water business.
\end{abstract}




\section{INTRODUCTION}

1. A rural water supply scheme (RWSS) has been one of the traditional, less costly, and easier to establish methods for providing access to acceptable drinking water to rural villages in developing countries. Types of RWSSs vary from simple community-dug wells to less sophisticated, small-scale piped water network, with standpipes, and even at places with metered pipe connections to households. A combination of affordability, availability of water, geographical nature, and institutional capacity decide on how a RWSS may be established in a location. Developing countries, including Sri Lanka, having recognized the benefits of RWSSs, continue to provide resources to create new RWSSs, as well as to improve existing ones.

2. However, due to lack of post-implementation support, RWSSs face drawbacks in their longterm sustainability. Unlike urban water schemes, RWSS operation and maintenance are not backed by formal and capable institutions. While donor agencies and the respective governments take leadership roles in project activities during implementation of RWSSs, this focus diminishes in the postimplementation stage. In most cases, rural community-based organizations (CBOs) and local authorities, which usually have financial, managerial, and technical capacity constraints, are left with the responsibility in maintaining their RWSSs. These make RWSSs less sustainable. Finding solutions to tackle post-implementation issues in RWSSs is paramount for sustainability.

3. Among the already available findings, the following two approaches have been analyzed in improving RWSS post-implementation sustainability.

4. Women participation. Women play an important role in water management and their contribution is greatly accepted. Because women are expert agents of change, they tend to achieve equitable access to water for all, and for all uses. For more than 2 decades, the role of women within the water sector has been examined and studied. Accordingly, it has been found that the most substantial improvements in the governance, transparency, and sustainability of water supplies are achieved when men and women are involved in equal measure as opposed to when women are involved only marginally or not at all (Narayanan 1995).

5. RWSS operations as a business model. The 1992 United Nations (UN) Dublin Conference on Water and Sustainable Development, proclaimed that water should be treated as an economic good (World Meteorological Organization 1992). Attaching value to water resources encourages proper management to help improve sustainability, which pertains to multiple aspects of a RWSS in institutional, social, technical, environmental, and financial dimensions. For a RWSS to be well managed in the dimensions of financial stability, operational efficiency, and sustainability, a CBO and/or local authority needs to understand the basics of running its RWSS operations as a business model.

6. Combining these two approaches, women with entrepreneurial traits in RWSS operations are sought to further improve RWSS sustainability. Thus, RWSSs, for their sustainability, seek rural women with entrepreneurial traits. Remarkably, such capable women could be found in the same rural background.

7. RWSSs provide easy access to safe water for women, improve their livelihood, and reduces their time poverty. Thus, rural women get more time to develop their productivity, practice business skills, 
and earn additional income for their families. In some instances, this positive push helps women who have inherent entrepreneurial skills develop their capacity and become successful rural entrepreneurs.

8. Given this context, rural women participating in RWSS operations and practicing their entrepreneurial traits creates a positive cycle of development. This positive cycle could bring mutual benefits to rural women and their RWSSs.

9. Based on the experience of the Asian Development Bank (ADB) in financing RWSS projects in Sri Lanka, this working paper puts forward the idea that RWSSs have become a platform for rural women to apply their entrepreneurial traits and asks whether the combination of water, women, and rural entrepreneurship could be catalyzed to ensure rural water system sustainability. This analysis, based on case studies, is qualitative and undertaken through literature reviews, focus group discussions with the local RWSSs members, interviews with key stakeholders, and secondary data collection. We hope this paper can trigger important discussion and, if warranted, further development in this research area.

\section{INTEGRATION OF WOMEN IN RURAL WATER SUPPLY OPERATIONS}

10. Women have become a significant force in a country's economic development. They contribute and support the economy extensively through employment across sectors. Women have proved to be productive economic actors, prudent decision makers, visionary leaders, compassionate volunteers, and constructive peacekeepers, and many women are expanding their horizons. They have become active in areas where they were not traditionally active, and they have excelled in every aspect of life where they are engaged, even in societies where women have faced great obstacles in overcoming their traditional roles (United Nations Development Programme 2016).

11. Specially, rural women everywhere play a key role in supporting their households and communities to achieve food and nutrition security, to generate income, and to improve rural livelihoods and overall well-being. Women and girls are the primary providers, managers, and users of water in many rural households. They spend less time learning in school or working in productive a economy, and more time in accessing clean water for their families or looking after loved ones affected by water-borne diseases. Hence, women have a major stake in water matters and must be part of any decision about water issues. Accelerated, expansive, and strategic efforts are required to address water security aiming at strengthening the efficacy of rural water resource management before the full weight of water-related disruptions fall upon women.

12. Women's leadership in the water sector matters since, as noted above, water is often considered "women's business" in many RWSS recipient communities, and so water is critical to the performance of these women's productive roles. The form that their leadership takes, however, is critical and it can only be effective if women shape and influence change. Women's empowerment is not about appointing women to token positions but giving them authority to influence decision making for the benefit of women as well as men.

13. Women's involvement and leadership in rural water sector have been proved to be successful. But with emerging threats in getting clean water, is women's leadership in the rural water sector 
enough for the long-term sustainability? As stated before, to empower women and for them to shape and influence changes, these women must follow and introduce new management trends, as well as test their own ideas. While replicating the already proven interventions of women into rural water sector issues, new combinations must be perused. Given the importance of entrepreneurial thoughts in managing rural water, allowing women with entrepreneurial traits in managing operations would be another such combination.

\section{ENTREPRENEURSHIP AS A SOLUTION TO SUSTAINABLE RURAL WATER SUPPLY SCHEMES}

14. The UN's sustainable development goal, number six, aims to ensure the availability and sustainable management of water and sanitation for all (UN 2015). This goal targets to achieve, by 2030, universal and equitable access to safe and affordable drinking water for all. However, this target seems hard to reach. The 2019 UN report indicate that there are still around 785 million people lacking even a basic drinking water service (UN 2019).

15. Providing safe, affordable, and sustainable water to all will continue to be a challenge, unless innovative and inclusive ideas are introduced into the traditional methods of providing and managing water. Most rural areas of developing countries face significant challenges in providing safe and affordable water to consumers through RWSSs. As indicated in the introduction section of this working paper, RWSSs face the biggest sustainability risks at the post-implementation stage. Sustainability of RWSSs depends on several technical, financial, and institutional factors.

16. Having a simplified treatment and distribution system, choosing a good water source, and timely maintenance of the distribution assets would be some of the things that increase the technical sustainability. Threats to the financial sustainability are very contextual and multifaceted. In general, RWSS operational costs are fully financed from the revenues collected from rural water users. In this sense, some of the smaller RWSSs, which have lesser house connections (around 100) need to impose comparatively higher tariffs to cover their total operational costs. In most rural contexts, payment of revenues does not happen on time. This becomes more severe when tariffs are higher and when the rural villages are affected by natural calamities (drought and floods affecting the entire livelihoods of the village). Given these challenges, it would be a necessity for a $\mathrm{CBO}$ and/or local authority to have a financial cushion to manage the financial surges in operating their RWSSs. Such a financial backup could be maintained in two ways. One would be to extensively save excess income and/or profits during good times and invest this on less risky bank deposits and use the payback to cover the shortages in bad times. The other way would be to diversify the income from other potential sources outside core water supply revenues. Given this diversification option, CBOs may opt for business activities at the rural level that may complement their core water operations (producing bottled water, providing sanitation services, trading plumbing hardware, etc.) or activities that are completely outside core operations (such as microfinancing for rural business activities).

17. Some of the institutional challenges toward sustainability would be a lack of transparency in the selection of CBO members to manage the RWSS and its financial transactions, the provision of a service not friendly or easy-to-use for customers, and exclusive decision making. 
18. As indicated initially, the 1992 Dublin Statement on Water and Sustainable Development, indicates that "[w]ater has an economic value in all its competing uses and should be recognized as an economic good" (World Meteorological Organization 1992). This statement recognizes that even though access to safe water is a basic human right, the service to provide such water needs to be offered at an affordable price. Failure in the past to distinguish the economic value of water has led to waste of the resource and uses that have been damaging to the environment. To achieve efficient and equitable use and encourage conservation of natural resources, water needs to be managed as an economic good. Charging for water is applying an economic instrument to affect behavior toward conservation and efficient water usage, to provide incentives for demand management, ensure cost recovery, and to signal consumers' willingness to pay for additional investments in water services (Global Water Partnership 1996).

19. Given the above challenges in supplying safe and sustainable water to the rural demand at an affordable price, the operations of an RWSS leads to the fundamentals of running a small business. This, moreover, seems to be requiring the idea of social entrepreneurship, which couples entrepreneurial behavior with the desire to draw upon the market as a tool for meeting social goals, serving the general interest and common good for the benefit of the community. Social entrepreneurship emerged as a response to complex social needs and the reduction in public funding. These types of enterprises draw on sound business practices and often innovation to the delivery of community services (Gero et al. 2013).

20. In brief, providing rural demand for safe and sustainable water has become a complex social need. Provision of such water at an affordable price requires water operations to be managed as business. However, the business process need not to be solely profit-oriented, but rather as a service to the community. Thus, exercising social-entrepreneurial traits in the operation of an RWSS is unavoidable.

21. Introducing entrepreneurial thoughts into RWSS operations is not something new. Many developing countries in Asia and Africa have already started practicing innovative entrepreneurial ideas as a mean for sustainability of rural water, sanitation, and hygiene (WASH) services. The following table illustrates some of the small-scale, rural-based WASH enterprises practiced in these regions.

Table 1: Examples of Water, Sanitation, and Hygiene Enterprises at Rural Level

\begin{tabular}{lll}
\hline \multicolumn{2}{c}{ Types of Rural Water, Sanitation, and Hygiene Enterprises } \\
\hline Water & \multicolumn{1}{c}{ Sanitation } & Hygiene \\
\hline - piped water service providers & - masons & - local retail stores \\
- water pump suppliers & - construction enterprises & - soap manufacturers \\
- water truck owners & - hardware stores & menstrual hygiene product \\
- hand pump manufacturers, & - sales agents (sanitation & manufacturers \\
$\quad$ installers, and maintenance & marketing) & distributors \\
- bervices & - fecal sludge emptying operators product \\
- water purification technology & - plumbing services & social enterprise franchises \\
\hline production and distribution & - prefabricated cement & \\
\hline
\end{tabular}

Source: Leahy et al. (2017). 
22. Enterprises, whether small, medium, or large, are all run by entrepreneurs. These entrepreneurs could be individuals or a group, but each have their distinguishable entrepreneurial traits and motivations. Given that RWSS operations need to be combined with entrepreneurial concepts, CBOs that run these RWSSs need to have management with entrepreneurial traits and motivations. Figure 1 illustrates some of the basic entrepreneurial traits that the literature references.

Figure 1: Basic Entrepreneurial Traits

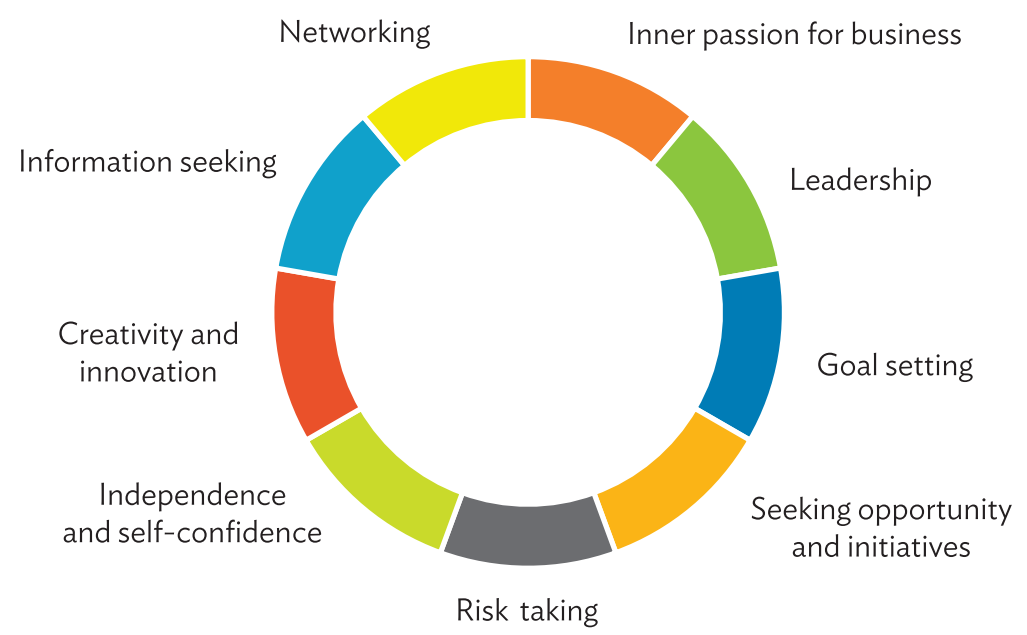

Sources: Willetts, Murta, and Gero (2016); and Yogendrarajah (2019).

23. While the argument about whether a person with entrepreneurial traits is born or made, it is generally agreed that the working environment of a person determines whether a person becomes a successful entrepreneur or not. Entrepreneurs need not be always naturally born but may be nurtured. While a balanced mix of the basic traits, as indicated in Figure 1, will be desired for a successful entrepreneur, not all entrepreneurs will have these traits to the required level. Based on the social and religious beliefs, entrepreneurship traits may vary among different social groups. The way that gender intersects with culture also impacts the entrepreneurial traits in women. Based on these differences, challenges faced by entrepreneurs vary between individuals within a single industry as well as between groups in different industries.

24. Adaptation of entrepreneurial concepts into RWSS operations will not be a panacea to all sustainability issues. However, considerable financial and institutional issues may be mitigated by using appropriate and timely entrepreneurial concepts. 


\section{THE SRI LANKAN RURAL WATER SUPPLY CONTEXT}

25. As of 2016, around 78\% of Sri Lanka's 21 million people live in rural areas. At a national level, $86 \%$ of the population have access to safe drinking water, with $46 \%$ having pipe-borne water. Out of the population that has pipe borne water, 35.2\% (mostly urban) are connected to national water distribution networks managed by the country's National Water Supply and Drainage Board (NWSDB). The balance (10.8\%) are served through CBOs and local authorities. Though the country has achieved significant progress in terms of access to safe water at the national level and has achieved Millennium Development Goal targets set for 2015, regional disparities in coverage of safe water still prevail. In terms of regulatory and administrative arrangements, the NWSDB, under the Ministry of City Planning, Water Supply, and Higher Education (MCPWSHE), is the national entity responsible for the provision of drinking water in the country by implementing large- and medium-sized, mostly urban, water supply schemes.

26. Rural water supply management responsibility has been shared among different agencies. The Department of National Community Water Supply (DNCWS) under the MCPWSHE oversees a partial responsibility, while the rest is taken care by the Rural Water and Sanitation Section of the NWSDB. In some areas, respective local authorities take full responsibility. There are around 4,000 RWSSs in Sri Lanka managed by CBOs and local authorities (Rural Water and Sanitation SectionNational Water Supply and Drainage Board 2017). Generally, NWSDB's Rural Water and Sanitation Section, through the section's respective regional support centers, provides technical support to CBOs and local authorities whenever needed. By end of 2020, the government aims to provide access to safe drinking water to all citizens and to increase access to pipe-borne water to $60 \%$ of the population. This will require the government to implement around 1,185 new RWSSs before the target year.

27. Achieving this target is not going to be easy. Establishing RWSSs through CBOs takes considerable time and effort. Institutional capacity constraints, delays in channeling funds, bureaucracy, overlap, and gaps in responsibilities, are only a few of these challenges. As indicated in the initial part of this report, post implementation of the RWSSs have their own drawback. Initial observations indicate that issues such as water shortage from the intakes, revenues less than operational costs, and CBO management improperly operating their RWSSs have been the main reasons that Sri Lankan RWSSs have been less sustainable.

28. In addition to these internal challenges, emerging external ones showed that the burden on the authorities in implementing RWSSs will increase with time.

29. From the mid-2000s, there has been widespread concern about a chronic kidney disease (CKD) in the country, largely in the North-Central Province and spreading to other rural areas. The impact of CKD of unknown etiology was first diagnosed in Sri Lanka in early 1990s. The disease has reached epidemic level. A Presidential task force has been appointed to address the issue. The disease is perceived to be due to contaminated drinking water, which has amplified the villagers' interest in pure drinking water, causing them to abandon their traditional natural water sources such as dug wells, streams, and even the primarily treated RWSS supplied water. They now opt for expensive treated water with reverse osmosis technology or commercially available bottled water. 
30. Because of global climate change, rural Sri Lanka is also facing the reality of large spells of drought and erratic monsoons. The government was forced, during the years 2015-2017, to distribute drinking water in bowsers to the drought affected rural areas of 11 districts in the North, East, North-Central, North-Western, and Uva provinces, and provide relief to farmers.

31. Nevertheless, having identified the importance of managing RWSSs in a sustainable manner, the following key strategy has been specifically planned for the development of RWSSs, as per the government's Public Investment Program for 2017-2020 (Government of Sri Lanka 2017):

Increase access to pipe-borne water supply facilities in rural areas through: promoting rural community-based water supply in the scattered villages; strengthening the DNCWS to ensure the sustainability of the community water supply schemes; and, strengthening the rural water supply units established in NWSDB's Regional Support Centers island-wide to support the DNCWS.

32. Having identified the requirement for women's participation for successful management of RWSSs, the government has stipulated guidelines in its national policies for such requirements. Accordingly, the principle policy specifies that "women should play a central role in decision making of the sector" (Ministry of Urban Development, Construction, and Public Utilities 2001). In addition, the NWSDB, in its circular to its district level RWSS officers, requests to 'encourage a focused process of women's empowerment though windows of opportunity opened by community water supply approaches' (Rural Water and Sanitation Section-National Water Supply and Drainage Board 2017).

33. Among the funding agencies, ADB and the World Bank have significantly assisted the Government of Sri Lanka in better implementing RWSSs. The government has also initiated its own funding to assist the latest RWSSs through the NWSDB.

\section{ADB'S ASSISTANCE TO SRI LANKAN RURAL WATER SUPPLY SCHEMES}

34. Since mid-1980s ADB has assisted the Government of Sri Lanka to achieve its water and sanitation targets. The first ADB-financed water relater project (Water Supply Sector Project, ADB 2007) was approved in November 1986. The second project (Second Water Supply and Sanitation Project, ADB 2007) was approved in February 1993 and had pilot RWSS components. With the success in this project, the next two ADB-assisted projects (Third Water Supply and Sanitation Sector Project, ADB 2009 and Secondary Towns Rural Community-based Water Supply and Sanitation Project, ADB 2016) had major components in assisting rural water supply and sanitation in the country.

35. Under the Secondary Towns and Rural Community-based Water Supply and Sanitation Project (fourth in the series, ADB 2016) additional RWSSs were implemented in the Anuradhapura and Polonnaruwa Districts. The project was initiated in early 2004 and assisted in establishing 228 CBO-managed RWSSs. The RWSSs were implemented through the NWSDB with the assistance of local nongovernment organizations (NGOs) and local authorities. While the NWSDB provided the technical designs and supervision, NGOs were responsible for the formation of $\mathrm{CBO}$ committees, the 
establishment of management setups, and the assistance to the new CBOs in starting RWSS operations. Technical officers from local authorities were trained in technical aspects of the RWSS.

36. During the project implementation period, women participated at different levels of designing, implementing, and operating their respective RWSSs. Women actively participated in all programs as at least $50 \%$ of participants, and in some cases more than $50 \%$. Women willingly donated labor required for infrastructure components and adjusted domestic and other responsibilities around this as they had time to plan participation in the work. In the early phase of project implementation, $25 \%$ targets for women's participation on project teams and implementation support NGOs were met. The requirement that $20 \%$ of trainees be women was also met. More women were present at all CBO meetings than men (ADB 2016).

37. At project completion, women's composition in the $\mathrm{CBOs}$ was almost equal to or, in some cases, more than men. In Anuradhapura, women made up 49\% of CBO executive committee members, and 52\% in Polonnaruwa. Participation in CBOs was 55\% women in Anuradhapura and 50\% in Polonnaruwa. Women's groups formed under the project were associated with the Women's Bureau of Sri Lanka and each group was given SLRs20,000 (about \$110) to commence selfemployment activities. This was mostly seen as inadequate to establish viable self-employment projects. A forum of women's associations for each local authority area was established. Links were made between the Women's Bureau and social development officers at steering committees within NWSDB. Some community development officers joined the CKD unit at NWSDB (ADB 2016).

38. Along with the provision of rural sanitation, this project benefited around 253,000 rural people. Close to $\$ 20$ million (about SLRs3.6 trillion) was invested in these rural water and sanitation outputs. By end of 2014, when the project was completed, 135 RWSSs (59\% of the total initiated) were functioning successfully.

\section{EVIDENCE OF WOMEN WITH ENTREPRENEURIAL TRAITS IN SRI LANKAN RURAL WATER SUPPLY SCHEMES}

\section{A. Case Study-based Analysis}

39. Scope. Integrating women entrepreneurs into RWSS operations is perceived to bring a positive development cycle and be an added approach for RWSSs sustainability. Given this proposition, the scope of this working paper is to peruse, through selected case studies, whether existing Sri Lankan RWSS contexts support this proposition. The study briefly and subjectively analyzes for how the RWSSs are organized to run as a business model; whether the local RWSSs have become a platform for women to practice entrepreneurial skills; how and to what level the RWSSs have allowed women to practice these entrepreneurial traits; challenges faced by women as entrepreneurs in RWSSs; whether the integration of women entrepreneurs into RWSSs has been beneficial to both the women and RWSSs; and how this integration could be improved for better results.

40. Data collection. Primary qualitative data on RWSSs was gathered through focused group discussions and interviews of key stakeholders of the $\mathrm{CBO}$ s and $\mathrm{CBO}$-employed staff who run the 
RWSSs. Secondary data was collected from CBO and RWSS organization booklets, training manuals, and annual reports. Additional information was collated from the staff of rural water and sanitation sections of the NWSDB, and the DNCWS of MCPWSHE. These data were collected during the third quarter of 2017. Data related to topics on entrepreneurship are solely based on secondary data gathered from literature.

41. Eleven RWSSs from the Anuradhapura and Polonnaruwa districts of the North-Central Province in Sri Lanka were selected for this study. All these RWSSs were functioning very well at the time of the study. Ten of these RWSSs were implemented under the ADB-financed Secondary Towns and Rural Community-based Water Supply and Sanitation Project, between 2006 and 2011. The remainder was implemented under the World Bank financed Second Community Water Supply and Sanitation Project in 2003 (World Bank 2017). Details of these RWSSs are provided in Table 2.

42. Study limitations. Though this working paper has helped to disseminate the project's initial aims, there are some limitations to this study. Based on the resources available and the time limit, this study has taken a very small sample, from the two districts of the country. All RWSSs, except one, are financed and implemented under ADB project implementation modalities. Therefore, to generalize the results for a larger group, a further study involving many RWSSs from other districts of the countryand financed and implemented through other agencies - should be carried out. Data collected for this study is more subjective and qualitative.

\section{Table 2: Details of Community-Based Organizations and Rural Water Supply Schemes Taken for Case Study}

\begin{tabular}{|c|c|c|c|c|c|c|}
\hline No. & CBO / RWSS Name & Location / Address & District & $\begin{array}{c}\text { Project } \\
\text { Financed } \\
\text { by }\end{array}$ & $\begin{array}{l}\text { No. of } \\
\text { Families } \\
\text { in the } \\
\text { Village }\end{array}$ & $\begin{array}{c}\text { No. of } \\
\text { Water } \\
\text { Connection } \\
\text { Provided } \\
\text { by the } \\
\text { RWSS }\end{array}$ \\
\hline 1 & Isuru Diya & 401, Thulana Hinguruwewa & \multirow[t]{3}{*}{ Anuradhapura } & \multirow[t]{10}{*}{$\mathrm{ADB}$} & 250 & 180 \\
\hline 2 & Samagi & 407, Thulana Pahala Thalawa & & & 290 & 170 \\
\hline 3 & Saliya Mala & 366, Thanthiri male & & & 385 & 150 \\
\hline 4 & Nelum Samadhi & $\begin{array}{l}\text { 81/82, Yudaganawa Nelum } \\
\text { Pokukna }\end{array}$ & \multirow[t]{8}{*}{ Polonnaruwa } & & 700 & 525 \\
\hline 5 & Nawa Dekkma & 98, Ataba Oya & & & 980 & 223 \\
\hline 6 & Pivithuru Jalakandha & 27, Ihakuluwewa & & & 604 & 190 \\
\hline 7 & Sanasum Nadiya & 13, Gangeyaya & & & 340 & 310 \\
\hline 8 & Segala Diyaulpotha & 10, Kottapitiya & & & 600 & 161 \\
\hline 9 & Nawodhya & 247, Rathmalthenna & & & 414 & 150 \\
\hline 10 & Arunodhaya & 243, Ihalawewa & & & 1,006 & 280 \\
\hline 11 & $\begin{array}{l}\text { Kalukele People's } \\
\text { Company }\end{array}$ & 217, Kalukele & & $\begin{array}{l}\text { World } \\
\text { Bank }\end{array}$ & 699 & 577 \\
\hline Total & & & & & 6,268 & 2,916 \\
\hline
\end{tabular}

$\mathrm{ADB}=$ Asian Development Bank, $\mathrm{CBO}=$ community-based organization, No. = number, $\mathrm{RWSS}=$ rural water supply scheme.

Source: Author's compilation. 


\section{B. Analysis Findings}

\section{Types of community-based organizations and their management structures}

43. In the national context, different types of CBOs are formalized to manage RWSSs. These RWSSs can be formed and registered as trusts, development societies, nongovernment organizations, or as small companies under the Sri Lankan Companies' Act (Ministry of Urban Development, Construction and Public Utilities 2001). Thereby, these CBOs are authorized to raise funds, obtain loans, receive grants, develop services, levy tariffs, and manage water and sanitation facilities subject to regulations and standards set by the government, provincial councils, and local authorities (Fan 2015).

44. All CBOs of the study had utilized these provisions to manage their water facilities. While initially the CBOs' mandate was to administer and oversee only the RWSSs, a few of them have evolved to take up other ventures of services to the community, outside basic water supply activities, like microfinancing. However, CBOs' levels of effort in exploiting these provisions to maximize the benefits were noted to be lower. For example, only one CBO was registered as a small company; and even though there were needs for financial assistance and the provisions permit, none of the $\mathrm{CBOs}$ have tried for a bank loan.

45. On analyzing the management structure of the entire RWSS operations, it was noted that there were two tiers. The top tier of operations was at the CBO's executive committee level. These executive committees were annually elected by $\mathrm{CBO}$ members and entrusted to oversee all of $\mathrm{CBO}$ activities including the administration of its RWSS. These committees then recruit a set of employees as the RWSS operations team. This RWSS operations team, at the second tier, is assigned with the day-to-day operational activities like management of the pump house, meter reading, revenue collection, etc. The RWSS operations staff are given monthly remuneration. Remunerations are paid from the rural water revenues. At times, members of the executive committee of the $\mathrm{CBO}$ are also involved in the day-to-day management of the RWSS. However, as per the CBO governance, members of CBOs' executive committees are not provided formal remuneration for their direct inputs, though some allowances were paid.

\section{Women's participation in rural water supply scheme operations}

46. Understanding the necessity of women's participation in RWSS operations, and their inputs in making decisions, the RWSS project implementation plans, starting from the initial planning stage, had enough provisions. The ADB-financed Secondary Towns and Rural Community-based Water and Sanitation Project had provisions for a minimum of $50 \%$ women participation in all RWSS activities, especially in the top management level of CBOs (ADB 2002).

47. The analysis of women's participation in RWSS activities were carried out at the two tiers observed in this study. First, women's participation in CBO executive committees was checked and the details are given in Figure 2. The number of members in $\mathrm{CBO}$ executive committees varied from a minimum of 6 to a maximum of 15 . The analysis found that six executive committees had more women members than men. One committee had equal members and another three committees had more men than women. Surprisingly, two of the committees had only women members which meant that all of the RWSSs operational decisions were made by women. Overall, women's participation in the case studies was more than men's, at 63\%. The most significant observation was that three CBOs in this study (Kalukele People's Company, Samagi and Pivithuru Jalakandha) were headed by chairwomen. 
Figure 2: Composition of Women in Community-Based Organizations' Top Management (Executive Committees)

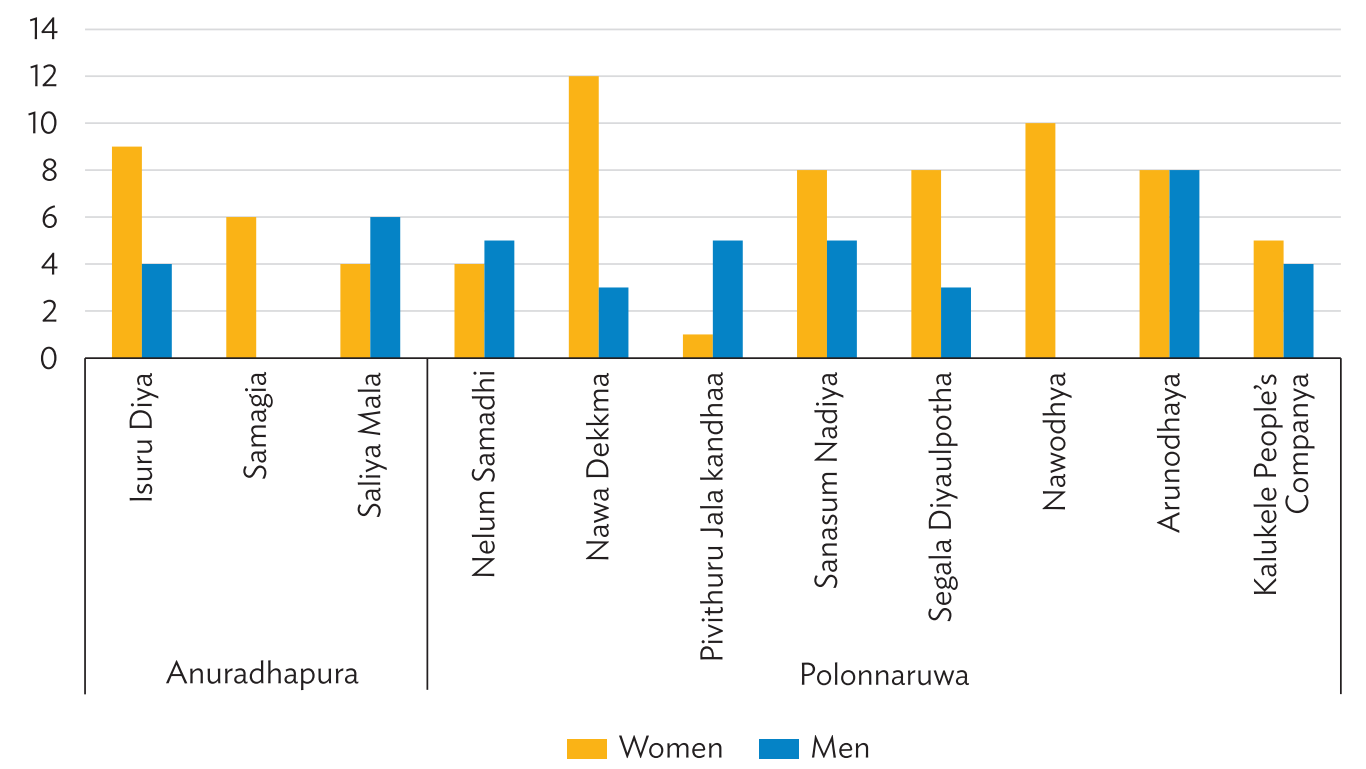

Source: Author's compilation.

48. The second analysis was done at the level of the RWSS operational staff team. Results of this analysis are given in Figure 3. Here again, the overall women's participation, at 61\%, was greater than the men's. Six operational teams had more women members than men. The Nelum Samadhi CBO had equal members and the Isuru Diya CBO had only 2 women running the RWSS operations on a daily routine.

Figure 3: Composition of Women in Rural Water Supply Scheme Operational Teams

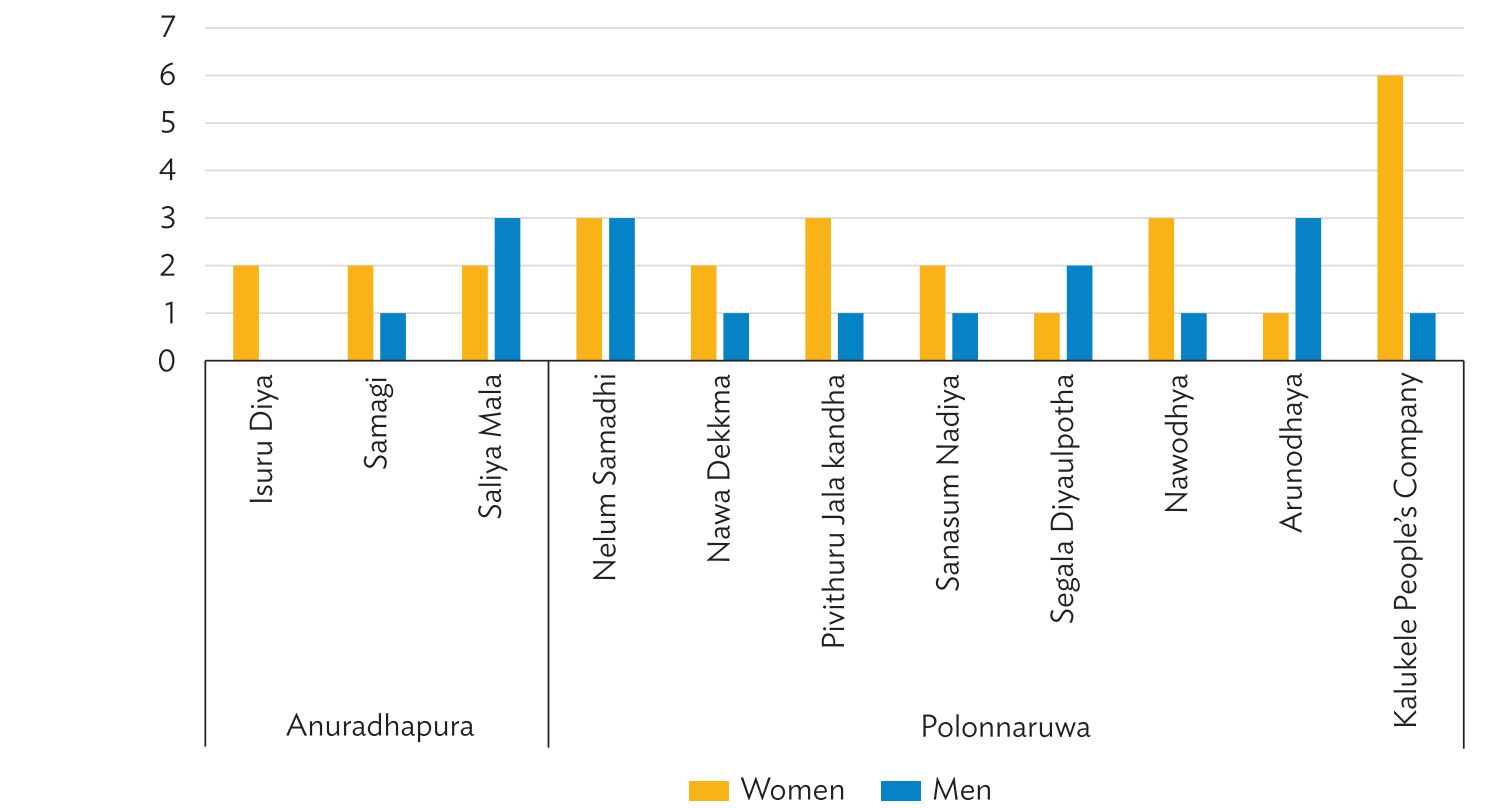


49. Overall the study indicated that more women participated in entire RWSS management than men. The study notes that around $60 \%$ of women participated in administering as well as in operating these RWSSs. This active women participation offered two major benefits. First, it benefited the rural women, by giving them a sense of achievement, for some, a livelihood, and for all, an improved capacity to do valuable work since they learned new knowledge (technical and managerial) that they normally could not gain in the rural context. Second, the RWSSs benefited from women's participation. Rural women's broader understanding of water usage helped the water schemes to be designed efficiently. Women contributed a considerable labor in constructing the infrastructure. Women's leadership role in the CBO's helped at times to solve social issues smoothly.

\section{Women practicing entrepreneurial traits in rural water supply scheme}

50. This section illustrates the findings of whether the women participating in the RWSS operations, considered for the study, have entrepreneurial traits and if so, whether the RWSS context had allowed them to practice their traits. The basic entrepreneurial traits listed in Figure 1 were considered. Analyses were carried out at the two tiers of RWSS management.

\section{(a) Inner passion for business:}

51. Every person has inner passion for something, whether it be their family, a business, or working on something. Passion is therefore critical to an entrepreneur's success. Entrepreneurs who convey passion are more persuasive, motivated, have larger social networks and more social capital (Baum and Locke 2004). As a result, they have more income, sales revenue and growth in sales and earnings compared with entrepreneurs who are less passionate (Baron 2008). Entrepreneurs must work long hours, sacrificing personal time for their business. Without the passion for the business, the struggle would be even harder.

52. Most of the women at the CBOs' executive committee level and RWSS operational team were highly passionate in working for their RWSS. Although the heads of CBOs were not required to work directly on RWSS operations and are not paid for such contributions, chairwomen of Kalukele People's Company and Ihakuluwewa CBOs were observed to be fully engaged and working on a routine basis, due to their inner passion. Many of the women working as RWSS operations staff were satisfied and motivated to be part of managing their RWSS since it earned them some respect among their community. It was observed that their commitment has led them to work for extra hours, voluntarily. These women stated they enjoy working for the RWSSs.

53. Few of these women had the passion to expand their water operations into small business entities and to achieve specific business goals, and most do not seem to identify themselves as emerging rural entrepreneurs to carry out their ideas.

(b) Leadership:

54. Leadership is becoming more and more important as a process that enables teams to engage in collective creativity toward the best possible outcome. All leaders do not become entrepreneurs. However, certain leadership skills linked to entrepreneurship include innovation, communication, vision and a proactive personality. These factors are vital to the success of any business venture (El-Annan 2013). 


\section{Box 1: A Woman's Passion to Run a Rural Water Business}

The following story of Maludena gedera Dayawathi, the chairperson of the CBO-Kalukele People's Company in Kalukale, Polonnaruwa district gave clear evidence of her passion for running her RWSS as a business entity.

A widow and mother of two, Dayawathi has lived all her life in the same village. She studied up to seventh grade and then joined as a laborer in a local gherkin cultivation institute. She worked there for 9 years and was promoted to quality controller, then to field officer, and finally, to storekeeper. She left this job after a few years and engaged in paddy cultivation. In 2003, under the World Bank financed Second Community Water Supply and Sanitation Project (World Bank 2017), a community-based organization (CBO) was formed and the RWSS was initiated. The $\mathrm{CBO}$ also started a community-based microfinancing scheme. In 2004, she was appointed as a director for livelihood activities of this project. She then earned a promotion to social mobilizer. Climbing up the management ladder, in 2013, Dayawathi was appointed as the chairperson of this CBO and made responsible for administering the RWSS. This was during a period when the RWSS was struggling to survive. The RWSS did not have enough financial savings to cope with operational costs. At the same time the village was severely affected with the chronic kidney disease (CKD) and people were desperate for safe drinking water. When she took over RWSS operations, the RWSS had only 370 household connections and the RWSS bank savings was just SLRs750 (about \$4). Electricity supply to the RWSS was disconnected due to unpaid bills. Savings from the micro financing scheme was SLRs600,000 (about \$3,306).

Dayawathi's commitment toward the village and her inner passion in managing the water system drove her to lead the RWSS to a better status. She conducted an awareness program in the village and made around 200 new water connections. She invested the CBO's financial savings back into RWSS operations. She also wrote to the President of Sri Lanka about her village's plight over the CKD issue, and as a result the $\mathrm{CBO}$ received a reverse osmosis plant. With her initiatives, RWSS operations picked up very fast. Reverse-osmosis-treated drinking water, as well the other pipe-borne water from the original RWSS, was supplied to villagers at a reasonable price. The revamped RWSS supplied safe drinking water to adjacent villages too. Through her initiative, 38 CKD patients in her village got drinking water at free of charge. The CBO also gave free drinking water to the village's school, temple, and medical clinic. She recruited six women to the staff of the RWSS operational office and trained them to run the office efficiently.

Thanks to Dayawathi's inherited entrepreneurial skills, the CBO continued to operate successfully and now a has savings of SLRs1.1 million (about \$6,060) from the RWSS operations, and SLRs3.9 million (about $\$ 21,482$ ) from the microfinancing scheme. Dayawathi recalled earlier times when the villagers had to face many problems in accessing water. She, along with the other women, had to go far away from the village to seek water, which proved difficult due to elephant attacks in the evening. She is now very pleased that her villagers do not face such problems. She enjoys being occupied full time on the RWSS work. Her long-term goal is to provide safe water to her entire village through the RWSS and to make the CBO more financially sustainable. Her RWSS is looking for more financial assistance to invest in two more water intake wells, and to purchase a suitably sized electric generator for her RWSS to run without the electricity crisis. 
55. Undoubtedly, the study witnessed high standards of female leadership in managing RWSSs. Women, as heads and prominent members of CBOs and RWSS operational teams, had full control of over the RWSS activities. They led teams in solving issues, and senior members guided younger members in the best practices. However, there seemed a considerable gap between women identifying themselves as goo d leaders in managing RWSSs and women identifying themselves as entrepreneurs. Focus group discussions showed that women tend to see leadership skills as something they have naturally, but entrepreneurial skills as something they need to inculcate from an external source. The perceived lack of entrepreneurial skills in these female leaders makes them less opportunistic in investing their leadership skills when making their RWSSs more financially sustainable.

56. One of the reasons these women consider themselves social leaders rather than rural water entrepreneurs may have to do with project design and the design of the CBO setup. The gender action plans of the ADB-financed Secondary Towns and Rural Community-based Water Supply and Sanitation Project indicated that the project was planned to involve more women in the formation and administration of CBOs in managing their RWSSs. Various trainings on leadership and technical skills were provided to women prior and during the implementation of RWSSs (ADB 2016). Even trainings on income generation and self-employment at household levels were also provided. But the trainings were limited to soap making, exercise books production, packaging food items, handicrafts, and animal husbandry. Classes on household financial management were also provided to women. However, there seemed no provision in these activities for women to utilize the entrepreneurial opportunities within RWSS operations.

\section{Box 2: More Than Just a Farmer and a Housewife}

Most residents of Pahalathalawa village in Thalawa, Anuradhapura district are farmers. They depend mainly on Chena cultivation (the most primitive type of agriculture, where cleared jungle lands are used for cultivation on rotation) and experience a very difficult life. Finding safe and adequate drinking water was an added burden to the villagers. The local well water contains high concentration of fluoride. As a result, many of the villagers have stained teeth and some had occasional urine infections. In the later stages, few of the villagers even developed with kidney diseases. The village women, in addition to their routine domestic work, assist their spouses in cultivation activities. Fetching water for their families consumed a great amount of their time. Even though several of these women desired to learn new skills and lead in social activities, they did not have the time or the opportunity to do so.

The ADB-financed Secondary Towns and Rural Community-based Water Supply and Sanitation Project in 2009, not only provided a solution to the village's drinking water problem, but also empowered women who wanted to be more than just farmers and housewives. The project implementation activities incorporated women as part of decision-making bodies. With the required training from the rural water supply division of the Anuradhapura National Water Supply and Drainage Board (NWSDB) office, these women implemented their rural water supply scheme (RWSS). They formed the community-based organization ( $\mathrm{CBO}$ ), planned project activities, managed finance, engaged in construction activities, and ultimately executed their water supply project with success and pride. They did not stop there. A few of the women engaged themselves in managing the RWSS by taking up managerial positions.

Mudiyanselage Dayawathi, whom researchers met, was a widow and a mother of four children. She was indeed ambitious and expressed entrepreneurial thoughts about how she wanted to expand her RWSS using her ideas. She initially joined the Samagi RWSS project as a volunteer supervisor and was given formal membership in the CBO in 2010. She gradually climbed the management ladder and 
became the chairperson in 2015. While she took over the leadership, the CBO had virtually no money to run the RWSS. Even though the RWSS initially gave connections to 83 households, in the following years this number reduced to 63 , as some households could not settle their dues and the house connections needed to be disconnected. Due to the poor revenue, the RWSS also became inefficient. She had plans to revive the rural water business. Through her persistent search, and with the assistance of the rural water supply division of the Anuradhapura NWSDB office, she found a donor-an Australian individual-to finance a reverse osmosis plant. With the operation of the reverse osmosis plant she quickly changed the financial condition of her CBO. She now sells around 800 liters of reverse osmosis treated water daily. With the operations of the original RWSS and with the new reverse osmosis plant, the CBO now earns around SLRs45,000 (about \$248) monthly. After paying the operational costs and wages to the staff, she now maintains around SLRs200,000 (about \$1,102) in her CBO's account. Her CBO's top management is entirely made out women and it employs three staff to manage the RWSS operation. While the manager and meter reader are women, the pump maintenance work is carried out by their male colleague.

Dayawathi does not get a constant monthly wage from the RWSS operations. Now that her four children are grown up and employed, she is more engaged in the rural water business to fulfill her self-satisfaction than to earn. Every day she opens her RWSS building at 6:00 a.m. for business, and closes at 6:00 p.m. Her entrepreneurial skills go beyond her water business. Whenever she finds time, she engages herself in sewing and selling products like bags, mosquito nets, and simple women's dresses. She also continues to cultivate to get an additional income.

While her ultimate plan is to develop her rural water business by increasing the capacity of the current reverse osmosis plant, she mentions with a smile her two competitors: one individual from her own village sells reverse osmosis treated water at a small scale; and an adjacent village's CBO sends a small mobile truck to her village to sell reverse osmosis treated water. She is also planning to hire and/or purchase a mobile truck to supply water from her RWSS.

Source: Interview with Hitihami Mudiyanselage Dayawathi. (December 2017). Thalawa, Anuradhapura.

\section{(c) Goal setting:}

57. Setting long-term goals and moving toward them are essential for growth, for every person and association. To achieve higher standards, key goals are needed. These key goals need to be broken down to smaller sub goals which can be achieved over shorter periods. This goal-setting approach leads individuals and organizations to derive their own vision and mission statements and to abide by them. Some entrepreneurial goals might be achieving a certain financial or asset ownership status, achieving better business investment and/or diversification, and taking certain business-related risks. Developing an attractive and attainable business plan is a must for any entrepreneurial body.

58. The women in the CBOs studied had their own goals, for themselves and for the group. Most women had the overarching goals to serve their village by providing safe drinking water and sustain their RWSSs into the future. However, most of these goals were for the short-to-medium term and were more objective in nature. Entrepreneurial goals were generally lacking in the CBOs. However, a few of the novel answers to the focus group discussion showed hidden entrepreneur goals held by these women. The Kalukale People Company and Samagi CBO's conveyed their goal in setting up their own water bottling facilities. The Sanasum Nadiya CBO in Polonnaruwa District wants to diversify its 
business by selling plumbing items and putting up a new communication shop (a local place to make telephone calls and do printing, photocopying, and other similar activities for a cost).

59. But, when digging deeper into their progress in achieving their goals, these women did not have the required knowledge on how to proceed with their entrepreneurial goals. The lack of knowledge in preparing a business plan and crafting an implementation schedule inhibited women from achieving these goals. Nevertheless, great potential in entrepreneur goal setting was witnessed among these women. It was delightful to see that the Kalukele CBO was proud to have its own written vision and mission statements and tried to reflect them in its operational activities.

\section{(d) Risk taking:}

60. Risk taking is an important component to growth and success. In entrepreneurship, risk taking is unavoidable. One perspective of this trait is that entrepreneurship concerns decision-making under conditions of uncertainty, and thus, entrepreneurs are inherently risk-takers.

61. Forming $\mathrm{CBO}$ s and their respective RWSSs contained many levels of risks. Some risks were technical, and others were social, financial, and managerial. All these linked back to the main risk-the sustainability of the RWSS. As elaborated in the introduction of this report, the risk to the sustainability of an RWSS increases with time. The lower risk during the implementation phase is associated with the great amount of external resources put into the implementation phase of an RWSS. As these resources diminish in the post-implementation phase, the risk increases. For RWSS sustainability in the postimplementation phase, the CBOs themselves need to lower risks by ensuring best practices, such as incorporating entrepreneurial concepts into RWSS operations.

\section{Box 3: A Seasoned Leader, Teacher, and Risk Taker}

Before the Piwithuru Jalakandha RWSS of Ihakuluwewa village in the Polonnaruwa district was implemented, like many women of her village, Chandra Dharmakeerthi, spent much time looking after her children and fetching water for her family. She joined the $\mathrm{CBO}$ as the first chairperson, implementing the ADB-financed RWSS. She was directly involved in the project's planning and monitoring activities. She continues to manage the CBO and RWSS activities.

She referred to the implementation phase of the RWSS and how the activities like project planning, decision making, and organizing resources were specifically carried out to involve many women from her village. This approach provided the opportunity for her and her fellow women to raise self-esteem and build confidence in themselves and their society. Since they became involved in the project activities from its initial stages, they received training in many aspects of RWSS management, such as technical maintenance, bookkeeping, and leadership skills. As a seasoned leader now, Chandra continues to train and teach her skills to her subordinates, including the three women employees of the RWSS operations office.

As the first chairperson of the $\mathrm{CBO}$, she took great risks in setting up the $\mathrm{CBO}$ and starting the RWSS initial operations. During this period, she pawned her own jewelry to finance gaps in the RWSS activities until the CBO raised revenues from the RWSS and settled her debt. She was also bold enough to bring her village community to a common stand in implementing the RWSS, although different groups had their own perspective on how to implement the RWSS.

Source: Interview with Chandra Dharmakeerthi. (December 2017). Ihakuluwewa, Polonnaruwa. 
62. Women in this study, as leaders and emerging entrepreneurs in the rural water business, took considerable risks in sustaining their RWSSs. The chairperson of the Piwithuru Jalakandha CBO pawned her own jewelry to fill the financial gaps in the initial implementation activities of her RWSS. The Kalukele People's Company and Nelum Samadhi CBOs took the risk of reinvesting water revenues into village microfinancing activities.

\section{(e) Seeking opportunity and initiative:}

63. Entrepreneurs take actions beyond job requirements. They create ideas that bring about phenomenal changes and are quick to see and seize business opportunities.

64. Originally the ADB-financed Secondary Towns and Rural Community-based Water Supply and Sanitation Project expected RWSSs to operate on simple pipe-borne water network schemes and their operational expenses to be covered by the revenue collected from water users. But the emergence of CKD in the villages at a latter part of the project increased the demand for safe drinking water. As an initiative by the government to counter the CKD issue, some of the high functioning RWSSs in these villages were provided with small reverse osmosis plants (with a production capacity of 10,000 liters per day). While villagers continued to use pipe-borne water from the RWSS for other purposes, they preferred the reverse osmosis treated water for consumption. Adjacent villages that did not have the reverse osmosis plants also approached RWSSs that had reverse osmosis plants. Compared to the RWSS-supplied pipe-borne water, reverse osmosis treated water was expensive, but people were ready to pay extra, knowing the consequences of CKD.

65. These events became a good opportunity for RWSSs to make extra revenue, as well to provide services to communities at a broader level. All the CBOs of the study had reverse osmosis plants and their operations were noted as very successful. $\mathrm{CBO}$ s that initially started selling reverse-osmosis-treated water to consumers at the RWSS offices, later arranged selling this water through small improvised bowsers to the village. This expanded through the provision of water to adjacent villages. Some CBOs purchased the required small trucks for these improvised bowsers, while the others continue to rent them for a cost.

66. Capitalizing on the demand for the reverse osmosis treated water, the Kalukale People Company and Samagi CBOs wanted to take further steps to initiate water bottling plants in their CBOs. However, due to their limitation in getting adequate support and/or advice on legal and technical aspects, their initiatives have not grown to a full business plan.

67. Opportunities to expand water-based business activities allowed CBOs to initiate their activities beyond their village levels. Based on the Samagi CBO initiative, the rural water supply division of the Anuradhapura NWSDB office got a donor, an Australian individual, to finance the reverse osmosis plant. The Saliya Mala CBO got its reverse osmosis plant constructed through a local bank's assistance as part of the local bank's corporate social responsibility program.

68. The demand for safe drinking water not only gave opportunity to the CBOs, but it also attracted few other local entrepreneurs. The progress in private persons starting up small-scale reverse osmosis plants and selling water within the same village was noted as a significant competitive factor to $\mathrm{CBO}$ business activities.

69. While the opportunities for water-based business activities played a significant role in expanding $\mathrm{CBO}$ operations, some $\mathrm{CBO}$ s went further in expanding and diversifying their activities into 
non-water-based business operations. One such operation was village microfinancing. Through these microfinancing schemes, CBOs give small soft loans to its members for members' individual needs. Initial investments for this financing scheme were usually received from either the savings of RWSS revenues, or seed money from another source (donations from NGOs, contribution from the CBO members, etc.). Women leaders in the $\mathrm{CBO}$ s showed a great support for this business opportunity. The survey found that all eight CBOs in the Polonnaruwa District and the Saliya Mala CBO in the Anuradhapura District had microfinancing schemes in their operations. Exploring another avenue of business diversification, the Sanasum Nadiya CBO wants to invest in opening a communication shop and a hardware store selling plumbing items to the villagers.

70. The survey noted that the CBOs had different levels of attraction toward the two different types of business opportunities: water-based and non-water-based (microfinancing, communication shop, etc.). Understanding the priority of the water-based business model, it should be noted that water-based business activities shall not become comparatively less attractive.

(f) Independence and self-confidence:

71. The need for independence relates to an individual's preference for decision-making autonomy and for avoiding rules and potential limitations of organizations. Self-confidence is simply an external manifestation of one's perception of self-worth. Typically, entrepreneurs need to have decision-making autonomy, although, unlike employees, they make decisions independently about their business goals and plans of action.

72. Women in the executing committees of $\mathrm{CBOs}$, especially chairwomen, had the independence required to initiate appropriate business activities; however, moving down the chain of command, ordinary members of the CBO and employees of RWSS operational offices had limited independence over their activities. This was noted to be common as women at these lower levels need to abide by the regulations of their $\mathrm{CBO}$ and RWSS employment.

73. The investigation on how well women in the RWSSs, as emerging entrepreneurs, balanced their work with their lives, led to some interesting findings. The two chairwomen of Kalukale People's Company and Piwithuru Jalakandha CBOs, who were observed to be vibrant emerging entrepreneurs, were in their early fifties and confirmed in their interviews that they have completed their major family commitments. Their children had grown up, married and were independent. These women had enough time to commit themselves in the RWSS activities, try out new things, and to enjoy carrying out their duties. However, the situation of young women in RWSSs was different. It was observed that young women as wives and mothers had limited time to be part of the RWSS activities, to try out new things, or to emerge as entrepreneurs.

74. Nevertheless, the RWSSs still provided opportunities for these young women to be 'intrapreneurs.' Compared to an entrepreneur, an intrapreneur is considered an entrepreneur within a larger firm, who uses entrepreneurial skills without incurring the risks associated with those activities. Intrapreneurs are usually encouraged to develop their ideas into a workable product by the companies they work for. Like an entrepreneur, an intrapreneur is motivated, creative, and able to think outside of the box. Nelun Samadhi and Sanasum Nadhiya CBOs were two exemplary examples for young women practicing their intrapreneurial skills in RWSS operations. 


\section{Box 4: A Female Intrapreneur}

This case study is from the Gangeyaya village in the Polonnaruwa District. Like other villages in the district, access to sustainable safe water was one of the villagers' biggest priorities. In 2007, this village was chosen under the ADB-financed Secondary Towns and Rural Community-based Water Supply and Sanitation Project, for implementation of a rural water supply scheme (RWSS).

The whole village welcomed this initiative with much appreciation. The implementation of the RWSS was mostly entrusted to the women, knowing their commitment to community work. From the initial planning stages of the project, women were inducted to the project's long-term plans, such as installing a communityrun water storage tank and mapping out a distribution network to link the entire village to the water scheme.

Pushpa Kumari is one of the prominent women members of the community-based organization (CBO) who initiated the Sanasum Nadiya RWSS in their village. She completed her secondary education in the arts stream and took up tertiary courses in computer application and bookkeeping. In addition, she also undertook a short course on business planning and accountancy, conducted by the government's Entrepreneurship Board. After a 2-year period of working for an insurance company, she initially joined the $\mathrm{CBO}$ as a treasurer. After a few years, she worked as a water meter reader and in 2014 she was promoted to the post of manager of the RWSS office.

With her input as a manager, the RWSS now successfully provides pipe-borne water to 310 households with a daily supply of 91,000 liters. In addition, 24,000 liters of pure drinking water is also provided through the reverse osmosis plant. Her request to the CBO's executing committee to hire a small vehicle with a mounted water tank, to supply water to the neighboring villagers, was approved and is now in operation. With this successful operation, her CBO now boasts a total savings of SLRs1.7 million (about $\$ 9,363$ ). Pushpa has also initiated plans to diversify the CBO's business initiatives by setting up a communication shop and a small hardware store selling plumbing accessories.

With a monthly remuneration of SLRs16,500 (about \$91), she is very confident of her role in the RWSS operations. She is certain that she can manage any responsibility of the RWSS operation in the future. She feels safe in her position and hopes she can continue to try out new activities in the water business to expand its operations as well to learn from her failures. She feels that her current position allows her to honor her family commitment while trying out her lower-risk business ideas in the RWSS operations. She hopes to become the chairperson of her CBO one day and take up more responsibilities towards RWSS operations.

Source: Interview with Pushpa Kumari. (December 2017). Gangeyaya, Polonnaruwa.

75. All women engaged in RWSS activities, from the top of the CBO-level to the lower level of the RWSS operations, had a great sense of confidence in their respective roles. Should there be more assistance in building their intrapreneurial skills, their confidence could be further improved. Nurturing these young intrapreneurs in their RWSSs will give them the tools they need to become future entrepreneurs.

\section{(g) Creativity and innovation:}

76. Creativity and innovation can be defined as a person's interest and willingness to follow new and different ways of doing things, outside conventional forms. In terms of content, this can be related 
to the development of new products, new technologies, new services, new processes of production, new markets, new business models and/or organizational management approaches, or new research into a business organization (Willetts et al. 2016).

77. From the typical Sri Lankan village perspective, where agriculture is the main source of income, women in the CBOs and RWSSs of this study had a mixture of creativeness and innovations. While some were still struggling to use a computer to store data and to issue printed water bills, the staff of Nelum Samadhi RWSS office were using mobile phone-based Global Positioning System (GPS, a space-based satellite navigation system that provides location and time information, anywhere on the Earth, with help of global positioning-enabled satellites) technology to map out their current pipeline network. The three female staff members of this RWSS, along with their male colleagues, are trying to use these techniques to expand the pipe network with new connections. This initiative is still at a very early stage, but it showed the staff's ambition in using the latest technology. The Kalukele CBO acquired the skills of using additional electrical capacitors to run electric water pumps and, as a result, has reduced its utility payments. However, the common observation has been that, while these women have various ideas in their minds, without a strong catalyst, their ideas were not able to be presented and practiced.

\section{(h) Networking:}

78. Networking plays an essential part in the entrepreneurial environment. Entrepreneurs need to have a good network with their customers, suppliers, and all the other stakeholders in their business. Most CBOs have an informal networking setup with their stakeholders at the rural level (NWSDB, utility agencies, other $\mathrm{CBOs}$, and local administrative agencies) and a comparatively good relationship with their local banks.

79. The nature of the village environment ensures a good network between the RWSS and its customers. Word of mouth seemed to be the best tool for networking and when spreading messages from the RWSS offices to customers. RWSSs do not need many suppliers, hence networking with them is not as imperative. The water pumps in the RWSSs, however, require regular maintenance, and thus the RWSS offices had formal and regular communications with pump suppliers. Since the reverse osmosis plants are comparatively new, there is limited contact between the spare parts suppliers and the CBOs.

80. The Nelum Samadhi CBO played a major role when networking among the CBOs by accommodating many other $\mathrm{CBO}$ s in their village to discuss matters of interest and learn from each other's experiences. The NWSDB's field offices have been a great source in arranging these networking events.

\section{(i) Information seeking:}

81. Networking among the peers of the RWSSs operational groups and CBOs have been one of the great sources for receiving information. However, networking was mostly within the CBOs of the same district.

82. $\mathrm{CBO}$ s sought information on different matters, as per their priorities. Most CBOs wanted information on fresh financial assistance for their operational activities and to fill financial gaps, while others needed technical information to solve current issues such as higher electricity bills, finding new water sources, etc. A few CBOs were interested in information on business expansion and 
diversification. CBOs have also approached corporate agencies to be involved in the agency's corporate social responsibility activities and to gain funding. CBOs have also approached politicians and local authorities with similar requests. After the CKD issue, the media has become a good platform for these $\mathrm{CBO}$ s to spread their stories to other parts of the country.

83. The NWSDB's regional staff of the Rural Water and Sanitation Section has been the CBOs' main source for information. CBOs continually seek information from the NWSDB on matters such as government regulations, tariff structures, and financial assistance through development financing. The DNCWS also seems to have become an additional source for providing information.

\section{Challenges faced by women as rural entrepreneurs in the water operations}

84. Among other technical, financial, and institutional challenges, CBOs continue to better manage their RWSSs. The following problems were noted to specifically impact women in CBOs as entrepreneurs and/or intrapreneurs or practicing their related traits:

- Women at top management of CBOs (mostly as part of the executing committees), at their latter stages of adulthood, had enough time and freedom to commit, and try different entrepreneurial initiatives, but lacked formal education in developing their skills. In contrast, women at the lower levels of CBOs, as well as employees of RWSSs operational teams, who were either adults or young adults, had limited time and too many family commitments, which prevented them from thriving in the entrepreneurial activities of the RWSSs.

- Women who lead in this sector continue to weigh themselves only as leaders, not as rural entrepreneurs, even though they had the required traits and used these traits.

- The absence of a catalyst (in the form of a mentor or a gender expert on female entrepreneurship skills) who could guide, advise, help, and support for the women in the RWSSs to discover the business potentials of their RWSS operations.

- Women's empowerment was another factor to be concerned. Fear of failure was observed in most of the women in the study. In general, the women interviewed had ideas but were unwilling to try them for various reasons, mainly fearing the consequence of a failed attempt on a new endeavor.

- While women felt that during the implementation phase of the RWSSs, much prominence and some special training was given to their participation, this was not continued in the post-implementation stage. Because of this concern, new female members are reluctant to take up responsibilities, especially on the technical aspect of managing RWSSs.

- Some of the other common entrepreneurial challenges faced by women in the RWSSs are: a lack of knowledge in managing the RWSS as a business model; a lack of investment in diversifying the existing water business; gaps and overlaps in institutional policies and regulations over managing RWSSs; the late payment of revenues by the customers; the inability to impose disconnection in a village environment and, emerging business competition in the village where private individuals also began to sell reverse osmosis treated water. 


\section{CONCLUSIONS AND RECOMMENDATIONS}

85. The study justifies the proposition of integrating women entrepreneurs into RWSS operations for positive development. Within the study limitations, the results showed that successful RWSSs have made women's lives better, helped rural women lead in their lives, and positioned women as leaders in their communities. As a result, considerable women now participate in the management and operation of RWSSs. A few of them have even become chairwomen of their respective CBOs. RWSSs have also become a platform for these women to practice entrepreneurial traits. While women at the higher levels of the CBOs have taken full control of RWSS management and practice entrepreneurial ideas (although not fully acknowledging their potential), women at the next levels have also been assisted by RWSSs to be intrapreneurs. The RWSSs have also been benefitted by these women. Some the RWSSs, which were about to fall apart, have been revived by their women leaders. RWSSs' financial statuses have improved and new thoughts of income to CBOs have been drawn up.

86. However, women who have achieved in rural water operations seem to appraise their achievement more as leaders than as entrepreneurs. Even though the study identified women with basic entrepreneurial traits managing their RWSSs better, they feel that the challenges faced for them to emerge as entrepreneurs and to practice to their full potential, need to be addressed by external sources.

87. The project designs seem to have a few limitations in positioning RWSSs as business models and in tapping women's entrepreneurial traits for the sustainability of the RWSSs. Training women during the project implementation seem to have helped women become leaders in the RWSSs, though it did not help them self-identify as emerging entrepreneurs. The post-implementation phase of RWSSs also seems to have limited institutional provisions to encourage rural water operations as a business model. Even though the national policies on RWSS have clear provisions for women's participation on the post implementation activities, they seemed more subjective. Women's empowerment procedures through post implementation activities of RWSS does not seem to be in the project design.

88. With the limitation of this study's findings, the following recommendations are proposed for a better management of the local RWSSs with the integration of rural women entrepreneurs:

- The government needs to consider incorporating additional provisions to the existing RWSS policies for RWSSs to be considered and operated as small business models. Requirements must be made in the policies to specifically involve rural women, not just as leaders, but as entrepreneurs.

- Government and future RWSS project financiers need to consider, in their project designs, from the inception stage, RWSS operations as small business models. Accordingly, inputs from the local entrepreneurship development institutes (like the National Enterprise Development Authority, National Apprentice and Industrial Training Authority, and universities that have special departments dedicated to developing such skills) need to be involved in the project design and their inputs considered for identifying, developing, assisting project beneficiaries, and monitoring the entrepreneurial and/or intrapreneurial components of the RWSS projects. 
- Entrepreneurial skills must be included in the curriculum, mandatorily, of training programs for women to acquire skills related to RWSS operations, at pre- and post-implementation of the RWSS.

- For already existing RWSSs, the DNCWS and NWSDB need to incorporate entrepreneurial thoughts in their portfolio of assistance toward the CBOs.

- As identified, it would be beneficial to provide external resources (may be in the form of a shorter consultancy in which the consultant could act as a catalyst) to assist the existing RWSSs, especially those led by women, to transform RWSSs into potential entrepreneurial bodies. These external resources could also tap the internationally and nationally available resources to improve rural women's entrepreneurship (e.g. Women Entrepreneurs Finance Initiative).

- Women's empowerment needs to be done on a custom-based approached. For example, as identified from the study, senior women at the top tier of CBOs may mainly need mentorship in developing their entrepreneurial ideas in to action. Adult education and training may also be carried out simultaneously. For the young women working at the RWSS operational tier, more traditional vocational training programs could be proposed. Agencies can design these programs that are focused in providing core skills that can help them understand the value chain of the RWSS, the basics of microbusiness management, and operations.

- Solutions to RWSS issues, in the background of entrepreneurial concepts, could be assisted through opportunities and/or projects that are originally meant for other sectors. For example, the ADB-financed Small and Medium-Sized Enterprises Line of Credit Project (ADB 2017), which is mainly meant to make a credit line to small and medium enterprises located outside the Colombo District, borrowing for working capital, and led by women, could be accessed to borrow finance for the viable opportunities of the RWSSs in the two mentioned districts of this study. Likewise, similar projects that are not solely meant for the water sector could be accessed for potential assistance. 


\section{REFERENCES}

Asian Development Bank (ADB). 2002. The Report and Recommendation of the President to the Board of Directors-Proposed Loan to the Democratic Socialist Republic of Sri Lanka for the Secondary Towns and Rural Community-based Water Supply and Sanitation Project. Manila: Asian Development Bank.

2007. Sri Lanka Country Assistance Program Evaluation: Water Supply and Sanitation Sector Assistance Evaluation. Evaluation Working Paper. Manila: ADB. Available online at: https://www.adb.org/sites/default/files/linked-documents/cape-sri-watersupply-sanitation-sector.pdf.

2009. Completion Report: Sri Lanka: Third Water Supply and Sanitation Sector Project. Manila: ADB. Available online at: https://www.adb.org/sites/default/files/project-document/64602/28153-sripcr.pdf.

2016. Completion Report: Sri Lanka: Secondary Towns Rural Community-based Water Supply and Sanitation Project. Manila: ADB. Available online at:

https://www.adb.org/sites/default/files/project-document/198306/31501-013-pcr.pdf.

2017. The Report and Recommendation of the President to the Board of Directors-Proposed Loan for Additional Financing Democratic Socialist Republic of Sri Lanka: Small and Medium-Sized Enterprises Line of Credit. Manila: ADB.

Baron, R. A. 2008. The Role of Affect in the Entrepreneurial Process. Academy of Management Review. 33(2). 328-340.

Baum, J. R., and E. A. Locke. 2004. The Relationship of Entrepreneurial Traits, Skill, and Motivation to Subsequent Venture Growth. Journal of Applied Psychology. 89(4). 587-598.

El-Annan, S. H. 2013. Innovation, Proactive, and Vision Are Three Integrated Dimensions Between Leadership and Entrepreneurship. European Journal of Business and Social Sciences. Vol. 1, No. 12. pp 148-163.

Fan, M. 2015. Sri Lanka's Water Supply and Sanitation Sector: Achievements and Way Forward. Manila: Asian Development Bank.

Gero, A., N. Carrard, J. Murta, and J. Willetts. 2013. Private and Social Enterprise Engagement in Water and Sanitation for the Poor: A Systematic Review of Current Evidence. Working Paper 1. Sydney:

University of Technology; Institute for Sustainable Futures.

Global Water Partnership. 1996. Dublin-Rio Principles. Retrieved 6 August 2019 from https://www.gwp.org/contentassets/05190d0c938f47d1b254d6606ec6bb04/dublin-rioprinciples.pdf.

Government of Sri Lanka, Ministry of National Policies and Economic Affairs, Department of National Planning. 2017. Public Investment Programme 2017-2020. Colombo. 
Independent Evaluation Group - World Bank. 2017. Project Performance Assessment Report. Sri Lanka Second Community Water Supply and Sanitation Project (CH035). Project Performance Assessment Report. 26 June. Washington, DC: World Bank.

Leahy, C., J. Lunel, M. Grant, and J. Willetts. 2017. Women in WASH Enterprises: Learning from female entrepreneurship in Cambodia, Indonesia, and Lao PDR. Enterprise in WASH-Working Paper 6. Institute for Sustainable Futures, University of Technology. Sydney.

Ministry of Urban Development, Construction, and Public Utilities. 2001. National Policy for Rural Water Supply and Sanitation Sector. Colombo: Government of Sri Lanka.

Narayanan, D. 1995. Contribution of People's Participation: Evidence from 121 Rural Water Supply Projects. Washington, DC: The World Bank.

Rural Water and Sanitation Section-National Water Supply and Drainage Board. 2017. Statistical Guidebook-Community Operated Water Supply Schemes. Colombo: Government of Sri Lanka.

United Nations. 2015. Transforming Our World: The 2030 Agenda for Sustainable Development. Resolution adopted by the General Assembly on 25 September - Seventieth Session.

2019. [Webpage] Sustainable Development Goal 6, Ensure availability and sustainable management of water and sanitation for all. Progress of Goal 6 in 2019. Retrieved 30 July 2019, from https://sustainabledevelopment.un.org/sdg6.

United Nations Development Programme (UNDP). 2016. Human Development Report 2016_ Human Development for Everyone. New York: UNDP.

Willetts, J., J. Murta, and A Gero. 2016. Water and Sanitation Entrepreneurs in Indonesia, Viet Nam, and Timor-Leste: Traits, Drivers and Challenges. Enterprise in WASH-Working Paper 4. Sydney: University of Technology, Institute for Sustainable Futures.

World Bank. 2017. Project Performance Assessment Report: Sri Lanka-Second Community Water Supply and Sanitation Project. Washington, DC: World Bank.

World Meteorological Organization. 1992. The Dublin Statement on Water and Sustainable Development." Dublin: International Conference on Water and the Environment. 26-31.

Yogendrarajah, R. 2019. Exploring the Factors on Micro and Small Women Entrepreneurs' Success in Northern Province of Sri Lanka. International Journal of Accounting and Financial Reporting. Vol. 9. No. 1. pp 257-278. 


\section{Integrating Women and Entrepreneurship for Sustainable Rural Water Supply Schemes in Sri Lanka}

Rural water supply schemes (RWSSs) carry risks of unsustainability in their post-implementation phase. In Sri Lanka, the integration of rural women with entrepreneurial and management skills into RWSS operations is expected to help improve sustainability and begin a positive cycle of development. In a case study-based analysis, this working paper discusses how women from Anuradhapura and Polonnaruwa districts of Sri Lanka are successfully engaged in RWSSs, and to what level RWSSs have become a platform for them to actively apply their entrepreneurial and management skills.

\section{About the Asian Development Bank}

ADB is committed to achieving a prosperous, inclusive, resilient, and sustainable Asia and the Pacific, while sustaining its efforts to eradicate extreme poverty. Established in 1966, it is owned by 68 members -49 from the region. Its main instruments for helping its developing member countries are policy dialogue, loans, equity investments, guarantees, grants, and technical assistance. 